\title{
Justicia ambiental y acciones constitucionales: estudio del acceso a la justicia en el Páramo de Pisba*
}

\section{Environmental justice and constitutional actions: study of access to justice in the Páramo de Pisba}

\author{
Nancy Paola Montañez Aldana $1 \rrbracket \underline{\text { ORCID }} \underline{\text { CVLAC }}$, Juan Camilo González Borda $2 \llbracket \underline{\text { ORCID }} \underline{\text { VVLAC }}$

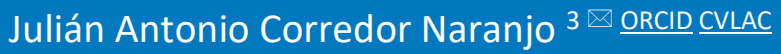

\begin{abstract}
* Artículo producto de los proyectos de investigación "El diálogo social como estrategia de desarrollo sostenible: resolución de conflictos medio ambientales: Caso de Estudio Páramo de Pisba en Boyacá" y "Participación ciudadana y gobernanza ambiental: el caso de las comunidades de Togüi y Samacá Boyacá".

${ }_{1}^{1}$ Magister en Gobierno y Políticas Públicas, Universidad Externado de Colombia. Docente Investigadora Fundación Universitaria Juan de Castellanos, Tunja, Colombia. Líder Grupo de Investigación Globalización y Derecho Hugo Grocio.

2 Magister en Derechos Humanos. Universidad Pedagógica y Tecnológica de Colombia. Docente Investigador Fundación Universitaria Juan de Castellanos, Tunja, Colombia. Grupo de Investigación Globalización y Derecho Hugo Grocio.

${ }^{3}$ Magíster en Derechos Humanos, Paz y Desarrollo Sostenible, Universidad de Valencia (España). Maestría en Derecho de los Recursos Naturales (en curso), Universidad Externado de Colombia. Especialista en Derecho Administrativo, Universidad Externado de Colombia. Abogado, Fundación Universitaria Juan de Castellanos, Tunja, Colombia.
\end{abstract}

Fecha correspondencia:

Recibido: abril 24 de 2021.

Revisado: septiembre 09 de 2021.

Aceptado: septiembre 10 de 2021.

Forma de citar:

Montañez, Nancy Paola; González, Juan Camilo y Corredor, Julián Antonio. "Justicia ambiental y acciones constitucionales: estudio del acceso a la justicia en el Páramo de Pisba" En: Revista CES Derecho. Vol. 12, No. 2, julio a diciembre de 2021, p. 107-130. https://dx.doi.org/10.21615/ cesder.6231

Open access

(C) Derecho de autor Licencia creative commons

\section{Resumen}

El presente artículo busca analizar el acceso a la justicia ambiental en el caso del páramo de Pisba, en Boyacá, haciendo especial énfasis en el desarrollo y materialización de la llamada justicia procesal. Para cumplir con lo anterior, en primera medida se aborda la conceptualización y evolución de la justicia ambiental desde un marco histórico; en segundo lugar, se analiza el aspecto procesal de la justicia ambiental como elemento relevante para garantizar la participación efectiva de los actores sociales; en tercera medida, se realiza una descripción y caracterización del ecosistema de Páramo de Pisba para finalmente, estudiar las acciones judiciales constitucionales relevantes, a la luz de la noción de justicia procesal ambiental. Se concluye la relevancia de la justicia procesal y el acceso a mecanismos judiciales como herramientas que moldean la protección de los ecosistemas paramunos y, así 
Ética de publicaciones

Revisión por pares

Gestión por Open Journal

System

DOI: 10.21615/cesder.6231

ISSNe 2145-7719

Publica con nosotros mismo, garantizan la participación efectiva de los diferentes actores.

Palabras clave: justicia ambiental; Páramo de Pisba; participación ciudadana; justicia ambiental procesal; acciones constitucionales.

\section{Abstract}

The present article seeks to analyze the access to environmental justice in the case of the Páramo de Pisba, in Boyacá, with special emphasis on the development and materialization of the so-called procedural justice. In order to comply with the above, firstly, the conceptualization and evolution of environmental justice is approached from a historical framework; secondly, the procedural aspect of environmental justice is analyzed as a relevant element to guarantee the effective participation of social actors; thirdly, a description and characterization of the ecosystem of Páramo de Pisba is made in order to finally study the relevant constitutional judicial actions, in the light of the notion of environmental procedural justice. The relevance of procedural justice and access to judicial mechanisms as tools that shape the protection of páramo ecosystems and guarantee the effective participation of the different actors is concluded.

Keywords: environmental justice; Páramo de Pisba; citizen participation; procedural environmental justice; constitutional actions.

\section{Introducción}

La evolución del concepto de justicia ambiental comprende el análisis de elementos sociales, políticos, culturales, ambientales y la reivindicación de derechos de comunidades desfavorecidas. De igual manera, se resalta la protección de la naturaleza y sus componentes, teniendo en consideración la tendencia a la declaración de los mismos como sujetos de derechos por algunos Estados.

La complejidad de su estudio nos remonta al concepto de justicia desde la antigüedad y a su evolución, donde han surgido derivaciones como la de justicia ambiental que enfatiza la protección de los recursos naturales desde el enfoque público y el privado, y en donde la participación ciudadana toma especial relevancia, así se promueve la suscripción de convenios y acuerdos internacionales que desarrollan la justicia ambiental y el cuidado de la naturaleza a 
través de principios como la sustentabilidad, partes iguales y mitad y mitad. Ello aunado al trabajo impulsado desde la CEPAL para el desarrollo de los pilares contenidos en el principio 10 de la declaración de Río, a saber: acceso a la información, participación en la toma de decisiones y acceso a la justicia.

Por su parte, los ecosistemas de páramos y alta montaña requieren total atención ya que juegan un papel fundamental en la sostenibilidad del sistema hidrológico y en la dinámica hidroclimatológica, por lo que varios estudios evidencian su necesaria relación con los pilares del principio 10. Así, la pregunta de investigación propuesta para este trabajo es la siguiente: ¿Cuál es el grado de materialización de la justicia ambiental procedimental en relación con la protección del ecosistema del Páramo de Pisba?; lo anterior dando especial atención a la relación del acceso a la justicia y particularmente el uso de acciones constitucionales interpuestas por los ciudadanos respecto a conflictos derivados en el Páramo de Pisba.

En este orden de ideas, el artículo presenta, en primer lugar, un recorrido por la historia del concepto de justicia ambiental, para dar paso a la taxonomía de justicia ambiental propuesta por Robert Kuehn y particularmente en los elementos de la justicia procesal, participación ciudadana, instrumentos legales y políticos de protección ambiental, explicando el concepto de acceso a la justicia, la normatividad internacional y nacional que lo cobija y su necesaria relación con lo jurisdiccional. En segundo lugar, se exponen las características de los páramos, centrando la atención en el complejo de páramos de Pisba. Posteriormente, se analizan las acciones constitucionales (Tutela y Popular) objeto de decisión por el Tribunal Administrativo de Boyacá y por la Corte Constitucional Colombiana, por medio de las cuales se define acerca de la delimitación del Páramo de Pisba, la necesidad de generarse un proceso participativo, abierto, deliberativo y consensuado con las comunidades que pudieren verse afectadas, estableciendo la relación entre la justicia procesal y el acceso a la misma por medio de las acciones judiciales.

\section{Metodología}

La metodología que se utilizó parte de un método deductivo con enfoque cualitativo, éste definido por Hernández Sampieri et al, como aquel que se "enfoca a comprender y profundizar los fenómenos, explorándolos desde la perspectiva de los participantes en un ambiente natural y en relación con el contexto." (2010, p.364). En este sentido, se analiza el concepto de justicia ambiental y su clasificación para luego hacer énfasis en la justicia procesal, concretamente en el acceso a la justicia a través del análisis de los fallos de acciones populares y de tutela interpuestas en relación con conflictos ambientales suscitados entorno a dicho ecosistema. 


\section{Justicia Ambiental: Un concepto desde la Complejidad}

Actualmente, no existe un consenso respecto a lo que se debe entender por justicia ambiental, sin embargo, la literatura jurídica y académica han decantado algunos aspectos esenciales que giran en torno a dicho concepto. Empero, antes de mencionar tales aproximaciones, es prudente mencionar en líneas concretas algunos elementos históricos relevantes que han contribuido a la formación del concepto de justicia ambiental.

Aproximadamente en la década de 1970, varias manifestaciones y reclamos de diferentes poblaciones en Estados Unidos lideraron lo que podría considerarse el antecedente primigenio del movimiento por la Justicia Ambiental. Los reclamos se fundamentaban en la excesiva exposición de ciertos grupos de poblaciones (negros, latinos, indígenas, entre otros) a sustancias altamente contaminantes. La anterior situación, eventualmente tomaría mayor presión social y política con ocasión de dos casos: El botadero de residuos tóxicos en Carolina del Norte, 1978 y, el caso "Love canal" en la comunidad de Niagara Falls del Estado de Nueva York. (Russ \& Krasny, 2017)

En el primer caso, había una exposición a desechos radioactivos que afectaban gravemente los medios de vida de la población y, en el segundo, se llega incluso al escenario en el cual, con ocasión de los desechos tóxicos y químicos que se mezclaron con aguas subterráneas, hubo afectaciones graves a la salud de la población causando defectos de nacimiento en algunos recién nacidos. Estas situaciones, sin duda, generaron indignación y el reclamo por medios jurídicos y políticos de las poblaciones que habitaban dichos escenarios geográficos. (Gosine \& Teelucksingh, 2008)

Lo anterior se entendió, por un sector social, como racismo ambiental, que, ligado al concepto primigenio de justicia ambiental, criticaba la exposición excesiva de la población negra y de bajos ingresos a niveles de contaminación realmente amenazantes de la salud y la vida humana. Como consecuencia de esta situación, el expresidente norteamericano Bill Clinton firmó la orden ejecutiva 12898 de febrero de 1994, que tomaba acciones político-administrativas desde el gobierno federal para abordar la justicia ambiental en las minorías y en las poblaciones de bajo ingreso. (Ruhl \& Ostar, 2016)

De esta manera, el concepto de justicia ambiental va tomando forma, en principio, como un llamado a la asignación justa y equitativa de las cargas contaminantes en la población norteamericana, tomando en consideración que todos los ciudadanos tienen el derecho a gozar un medio ambiente propicio y adecuado para el desarrollo de sus posibilidades. En esta línea, 
la Agencia de Protección Ambiental del Gobierno Federal Norteamericano, encargada de los asuntos ambientales, EPA, por sus siglas en inglés, ha proveído una definición de lo que puede considerarse como justicia ambiental:

"Environmental Justice is the fair treatment and meaningful involvement of all people regardless of race, color, national origin, or income with respect to the development, implementation, and enforcement of environmental laws, regulations, and policies (...)" (EPA, 2013, p.1)

Tal concepción se ha decantado por ampliar el espectro de participación ciudadana en los asuntos ambientales, como implementación, ejecución y creación de leyes y políticas en materia ambiental, lo anterior, sin ningún tipo de discriminación en razón a raza, color, ingreso económico u otra índole.

De esta forma, se consolida una de las posturas más determinantes del concepto de justicia ambiental, aquella que nace en Estados Unidos con ocasión de la oleada por los derechos civiles de la década de los 70 y que, como se describió ut supra, tiene una estrecha relación con el racismo ambiental o la discriminación por razones de ingreso.

En otra perspectiva, desde el escenario internacional, se ha buscado hablar de Justicia Ambiental como un reclamo o exigencia de los países en vía de desarrollo por la explotación indiscriminada de los recursos naturales de su territorio por parte de los llamados países del primer mundo y las empresas multinacionales. Es en este escenario, donde se encuentra uno de los debates más importantes de nuestra época, los riesgos y amenazas que la crisis ambiental actual presenta para los países menos desarrollados y que, particularmente, en poca proporción han contribuido al deterioro ambiental a nivel planetario. (Hervé y Rebolledo, 2013)

En ese sentido, es necesario incluir en su concepto componentes sociales, políticos, jurídicos, medioambientales, culturales e incluso económicos, entendidos todos ellos desde una concepción de complejidad (Ramírez, et al., 2015; Bellmont,2012). La justicia ambiental defiende y protege los recursos naturales desde lo público a partir de las políticas y la participación ciudadana, la judicialización de los conflictos y relaciones sociales, además vincula una cuestión ética, política, de ejercicio de la democracia y respeto de los derechos humanos (Ibarra y Moreno, 2017, p.141), implica el análisis de la desigualdad social y económica y los problemas ambientales derivados de ellas, comunidades en donde convergen generalmente 
estas problemáticas, además de soportar consecuencias y efectos negativos de la toma de decisiones en la que casi nunca participan, siendo necesario el reconocimiento de su condición y la distribución equitativa de las cargas (Hervé Espejo, 2010; Bellmont, 2012)

Por otro lado, en la jurisprudencia Constitucional ${ }^{1}$ la justicia ambiental se encuentra definida como "el tratamiento justo y la participación significativa de todas las personas independientemente de su raza, color, origen nacional, cultura, educación o ingreso con respecto al desarrollo y la aplicación de las leyes, reglamentos y políticas ambientales". (Corte Constitucional, 2018)

Así las cosas, la justicia ambiental comprende elementos de carácter ambiental, cultural y político, no puede reducirse a la esfera meramente ambiental desde la óptica de reivindicación o compensación por daños ambientales, tampoco a la lucha y defensa de los derechos humanos ejercida por parte de movimientos sociales. Autores como Mesa Cuadros (2018) insisten en la necesidad de remontarse a la idea de cultura, considerando el origen de la justicia ambiental "cuando una comunidad o sociedad se apropió injustificadamente de elementos de la naturaleza o el ambiente que pertenecían a otra comunidad, pueblo o sociedad" (p.30), es la propia cultura la que define el uso o abuso de los elementos de la naturaleza por parte de los seres humanos, lo permitido y prohibido (Mesa Cuadros, 2015)

\section{La taxonomía de la justicia ambiental propuesta por Robert Kuehn: hacia un entendimiento de la noción práctica de justicia en asuntos ambientales}

Como se describió en el apartado anterior, la historia y entendimiento de la justicia ambiental pueden llegar a ser temas complejos debido a la multiplicidad de factores que atañen las problemáticas ambientales. Pueden ser diferentes los puntos de análisis que buscan proveer de un marco interpretativo la justicia ambiental y su aplicación en la práctica legal. Si bien, el origen de la noción de justicia ambiental se circunscribe, usualmente, al movimiento por la lucha de los derechos sociales, así como el movimiento ambientalista de los Estados Unidos en los años setenta y ochenta, lo que provocó un notorio protagonismo en la esfera política y jurídica en dicho país, también se puede ver la noción de justicia ambiental, en el escenario internacional, como un reclamo de los países en vía de desarrollo por un trato más justo por parte de los países del llamado primer mundo y las multinacionales hacia el medio ambiente y los recursos naturales presentes en diferentes partes del planeta.

\footnotetext{
${ }^{1}$ La corte constitucional en la sentencia SU-123 de 2018 ha considerado que la justicia ambiental, dentro del marco de la Constitución, está compuesta por cuatro elementos interrelacionados: i) la justicia distributiva; ii) la justicia participativa; iii) el principio de sostenibilidad; y iv) el principio de precaución.
} 
Julio - diciembre de 2021

En este sentido, el profesor Robert Kuehn (2000) en su conocido texto A taxonomy of environmental justice presenta tal vez una de las aproximaciones más pertinentes para comprender los elementos y principios sustanciales que pueden integrar el amplio espectro de la justicia ambiental.

\section{En la tabla 1, se presenta tal clasificación con algunos elementos característicos que ayudan a entender los componentes de la justicia ambiental:}

Tabla 1. Clasificación justicia ambiental.

\section{Categorías justicia ambiental}

Justicia ambiental como justicia distributiva
Definiciones

Se puede afirmar que la justicia distributiva tiene que ver con la repartición de bienes y oportunidades dentro de los miembros de una comunidad. Así, en el contexto ambiental, la justicia distributiva puede hacer referencia a:

- La justa distribución dentro de los miembros de una comunidad de aquellos beneficios ambientales que provee el entorno natural.

- Una distribución justa de las cargas contaminantes que pueden llegar a generarse dentro de una comunidad. Este punto, sobre todo se asocia a los inicios del movimiento por la justicia ambiental que reclamaba el exceso de residuos tóxicos y contaminantes en algunas comunidades negras o de bajos recursos en Estados Unidos.
Justicia ambiental como justicia procesal
La justicia ambiental, vista desde una óptica procesal, involucra indudablemente el iter que usualmente requiere la toma de decisiones tanto políticas como jurídicas. Es decir, la justicia procesal, en este caso, se encuentra fuertemente asociada con la participación ciudadana en los asuntos ambientales y los mecanismos administrativos, políticos y jurídicos creados por el Estado como garantía de intervención de la ciudadanía en aquellos asuntos que puedan afectarles.

En este punto, podemos encontrar dos escenarios fundamentales: El primero, previo a la creación de las leyes y las políticas en materia ambiental y, el segundo, posterior a la implementación de dichas decisiones.

En los dos escenarios se deben garantizar los mecanismos de participación de manera efectiva, de tal manera que cualquier afectación a las comunidades o al medio ambiente en general pueda tener un tratamiento oportuno. 
Julio - diciembre de 2021

Categorías justicia ambiental

En el ámbito de la justicia correctiva se puede encontrar la facultad punible y sancionadora del Estado y sus agencias en aras de buscar una efectiva reparación de las afectaciones al medio ambiente $o$ a las comunidades.

Justicia ambiental como justicia correctiva

El principio rector de la justicia correctiva puede circunscribirse a dejar a la víctima (v.g. comunidades, individuos o el medio ambiente) en la condición previa en que se

\section{Definiciones} encontraba antes de la comisión del injusto.

Se puede asociar también la justicia correctiva, dentro del marco general de la justicia ambiental, con la justicia compensatoria, retributiva o restaurativa.

La justicia social, entendida como un componente de la justicia ambiental, recuerda el carácter ideológico del Estado social de derecho, al buscar garantizar las mejores condiciones ambientales para la sociedad en general $y$, buscando reducir los márgenes de desigualdad en los que pueden llegar a materializarse vulneraciones al derecho a un ambiente sano o a la salud de las comunidades.

Lo anterior, rompiendo un poco con el paradigma del tradicional Estado moderno donde la vida, la libertad y la propiedad privada podían verse como derechos supremos sin limitación alguna. Sin embargo, como se ha visto en los últimos años, la limitación a un derecho como la propiedad pueden ser necesarias en aras de garantizar un disfrute de derechos para toda la sociedad.

En la misma línea, la justicia social fundamenta parte de sus reivindicaciones en que aquellos "privilegiados de clase", puedan contribuir de manera más amplía al bienestar de la sociedad en su conjunto.

Fuente: Elaboración propia con fundamento en Kuehn (2000).

Así las cosas, la llamada taxonomía de la justicia ambiental permite resaltar aquellos elementos relevantes que involucran tal noción, en aras de permitir un análisis acertado de las realidades que actualmente viven los territorios en materia ambiental. Del mismo modo, la conflictividad actual en torno a los recursos naturales requiere partir de perspectivas que den cuenta de los diversos actores y motivaciones que yacen en la base de dichos conflictos, por lo que la participación ciudadana es fundamental y en Colombia los escenarios jurídicos como garantía de intervención de la ciudadanía en aquellos asuntos que puedan afectarles son vitales para la protección ambiental, por esta razón, para efectos del presente escrito, se hará hincapié en la justicia ambiental desde una óptica de justicia procesal. 


\section{Acceso a la justicia en materia ambiental}

La justicia procesal se relaciona de forma directa con el acceso a la justicia, la cual ha tenido importantes avances en las últimas décadas. En junio de 1992 la Conferencia de las Naciones Unidas sobre Medio Ambiente y Desarrollo proclaman la Declaración de Río, estableciendo en su principio 10 la necesaria participación de los ciudadanos para resolver las cuestiones ambientales, para ello, las autoridades públicas deben garantizar el acceso a la información, la participación en la toma de decisiones y el acceso a procedimientos judiciales y administrativos.

El Convenio de Aarhus o Convenio sobre acceso a la información, participación del público en la toma de decisiones y acceso a la justicia en materia de medio ambiente, firmado el 25 de junio de 1998 en la ciudad danesa de Aarhus, y que entró en vigor el 30 de octubre de 2001, para los países de la Unión Europea, es otro avance importante. Este convenio con alcance regional, pero con trascendencia global, regula el acceso a la justicia ante violaciones del derecho de acceso a la información y del derecho de participación en la autorización de actividades. También se describe el acceso a la justicia ante incumplimientos o violaciones de derechos ambientales por parte de autoridades públicas o de particulares. En este caso, los Estados parte del Convenio pueden establecer requisitos de acceso a los procedimientos judiciales.

Dentro de las disposiciones de este convenio está que cuando se tenga conocimiento de una actividad perjudicial para el medio ambiente o no se permita disfrutar de las garantías procesales, como el acceso a datos medioambientales, evaluaciones de impacto ambiental o participación pública, propias de un proceso de toma de decisiones, se puede denunciar tal situación ante un órgano jurisdiccional.

En América Latina la justicia ambiental se ha analizado a partir del equilibrio distributivo de los servicios ambientales y de soportar los efectos de la contaminación, destacando que muchas veces los que soportan más los daños ambientales son comunidades apartadas y marginales. (Bellmont, 2012, p.30). Para afrontar mejor una acción perjudicial o potencialmente perjudicial para el medio ambiente que tenga un impacto, por ejemplo, en una zona protegida o en la salud de los ciudadanos, hay que acudir, en ciertos casos, a entidades administrativas o a organismos jurisdiccionales.

El 4 de marzo de 2018, se adoptó en Escazú (Costa Rica), el Acuerdo Regional sobre el Acceso a la Información, la Participación Pública y el Acceso a la Justicia en Asuntos Ambientales en América Latina y el Caribe, más conocido como Acuerdo de Escazú, el cual contempla la 
obligación de cada Estado de garantizar el derecho de acceso a la justicia en asuntos ambientales en el sentido de que cada parte asegure "en el marco de su legislación nacional, el acceso a instancias judiciales y administrativas para impugnar y recurrir, en cuanto al fondo y el procedimiento" (artículo 8), y exhorta la promoción de mecanismos alternativos de solución de controversias ambientales. Estas disposiciones guardan estrecha relación con el Convenio de Aarhus, sin embargo, Colombia está pendiente de ratificarlo.

En el ordenamiento jurídico colombiano la justicia ambiental encuentra mecanismos legales y constitucionales para la protección de los derechos ambientales como las acciones que conoce la Jurisdicción de lo Contencioso Administrativo: nulidad simple, nulidad y restablecimiento del derecho, reparación directa, entre otros, y acciones constitucionales como el control de constitucionalidad, acciones de tutela, populares, de grupo y de cumplimiento relacionadas con el medio ambiente.

Para recurrir contra actos, decisiones y omisiones administrativas, es importante conocer las normas que permiten acceder a los órganos jurisdiccionales. En Colombia la constitución de 1991 reconoce el derecho a gozar de un ambiente sano y a la participación ciudadana en varios de sus artículos, y en el ordenamiento jurídico se han dado algunos logros en materia de protección medioambiental y de forma específica en la protección de los páramos. En el 2002, el ministerio del medioambiente expidió la Resolución 769, designando el estudio para la evaluación de los páramos a La Unidad Administrativa Especial del Sistema de Parques Nacionales Naturales, en conjunto con el Instituto de Hidrología, Meteorología y Estudios Ambientales y el Instituto de Investigación de Recursos Biológicos, Alexander Von Humboldt. Posteriormente, la Ley 1753 de 2015, fija la tarea de la delimitación de estos ecosistemas en cabeza del Ministerio de Medio ambiente y Desarrollo Sostenible, buscando aumentar el grado de protección, pero sin dejar de lado la posibilidad de su explotación.

En el año 2018, con la ley 1930, se establece que los páramos son ecosistemas estratégicos y se fijan directrices que propenden por su integralidad, preservación, restauración, uso sostenible y generación de conocimiento. Este mismo año, el Ministerio de Medio Ambiente por medio de la Resolución 2035, crea los centros regionales de diálogo ambiental, instancias de facilitación, articulación, participación, cooperación y reflexión para la identificación, priorización y discusión de los conflictos ambientales en el nivel regional. En el parágrafo del art. 1, de esta Resolución, se establece como conflicto socio ambiental, las "tensiones, desacuerdos o 
confrontaciones respecto al acceso, uso, manejo y protección de la biodiversidad, sus servicios ecosistémicos; la distribución de sus beneficios; la implementación normativa y el acceso o desconocimiento de información ambiental" (Guzmán Jiménez, 2018).

Como consecuencia de la diversidad de conflictos ambientales y la falta de eficiencia de los operadores administrativos y jurídicos para abordarlos, varias voces académicas y políticas proponen la creación de salas o tribunales especializados en materia ambiental, como se ha hecho en otras partes del mundo. Se "destaca la importancia de la preparación y capacitación de los jueces ante la complejidad (técnica y científica) de los conflictos ambientales y la naturaleza difusa de los derechos e intereses colectivos en la justicia ambiental" (Guzmán Jiménez, 2018, párr. 1). De igual forma, es fundamental garantizar la presencia de organizaciones no gubernamentales ante las instancias administrativas y judiciales, pues así se les permite desempeñar el papel de vigilantes y agentes medioambientales para la protección de un medio ambiente que no puede defenderse por sí mismo.

\section{Acceso a la justicia en el Páramo de Pisba}

En el complejo de páramos de Pisba se encuentran ecosistemas que se consideran estratégicos para preservar el derecho a disfrutar de un medio ambiente adecuado por su riqueza en biodiversidad y en recursos hídricos que hoy en día se consideran vitales, no solo para las comunidades que viven en sus alrededores sino para los ciudadanos en general. El acceso a la justicia en materia ambiental para resolver conflictos ambientales derivados de actividades como la minería y la agricultura en estas zonas de riqueza ambiental se pueden sintetizar en dos mecanismos: la acción de tutela que busca proteger derechos fundamentales, y las acciones populares, que buscan la protección de derechos colectivos.

\section{Ecosistemas de páramo}

Los ecosistemas de páramos y de alta montaña en general, son extremadamente vulnerables ante los efectos de la actividad humana, su proceso de transformación inició aproximadamente hace 10.000 años (Sarmiento, 2013). Los páramos son ecosistemas tropicales de montaña únicos en el mundo que se encuentran en algunos países de Suramérica y en Costa Rica; reconocidos principalmente por su singularidad biológica, sus recursos hídricos y los servicios ambientales que prestan a la población; además, son importantes por el almacenamiento de carbono atmosférico que ayuda a controlar el calentamiento global. (Greenpeace Colombia, 2013). Los ecosistemas de páramo, además de ser únicos por sus niveles extraordinarios de biodiversidad, proveen de agua para consumo humano y actividades agropecuarias a más del $70 \%$ de la población colombiana. (Sarmiento, et al., 2017) 
En el artículo 2 de la Resolución 769 de 2002 del Ministerio de Ambiente y Desarrollo Sostenible define el páramo como un ecosistema de alta montaña, ubicado en el límite superior del bosque andino, en el cual domina una vegetación herbácea y de pajonales, frecuentemente frailejones, donde pueden existir formaciones de bosques bajos y arbustivos, y presentar humedales como ríos, quebradas, arroyos, pantanos, lagos y lagunas. Comprende tres franjas de orden ascendente: el subpáramo, el páramo y el superpáramo.

\section{El complejo de Páramos de Pisba}

El complejo de páramos de Pisba está localizado en los departamentos de Boyacá y Casanare sobre el eje de la Cordillera Oriental y se extiende a lo largo de la zona nororiental entre los 3.100 y 4.100 msnm. De acuerdo con el Instituto Alexander Von Humboldt este ecosistema cuenta con una superficie de 106.243 ha., comprende territorios de 11 municipios, principalmente los de Socotá, Chita, Tasco y Socha (Boyacá) e incluye localidades como los páramos de San Ignacio, El Chuscal, Pisba, entre otros. (Sarmiento, 2013).

El Páramo de Pisba al conectarse con el páramo de El Cocuy conforma el corredor de páramo de la cordillera Oriental, que se caracteriza por presentar un gran número de ecosistemas naturales con gran riqueza biológica e hídrica en un relieve muy variado. (Greenpeace Colombia, 2013). Además, este complejo alimenta los acueductos comunitarios de distintos municipios.

La totalidad del área del complejo de Páramo de Pisba se encuentra en el territorio que deben proteger las autoridades ambientales en cabeza de las corporaciones autónomas regionales de Boyacá, CORPOBOYACÁ, 99,1\% y de la Orinoquia, CORPORINOQUIA, 0,9\%. Adicionalmente, 26,6\% del área del complejo se encuentra dentro del Parque Nacional Natural Pisba, declarado como tal desde 1977 y cuyo manejo está a cargo de la Unidad Administrativa Especial denominada Parques Nacionales Naturales de Colombia (Defensoría del pueblo, 2014). El área de superficie aproximada del Parque es de 45.000 ha., y sus límites se encuentran en las jurisdicciones de los municipios de Socotá (79\%), Socha (3\%), Tasco (4\%), Pisba (1,8\%) y Mongua (12,2\%). (Parques Nacionales de Colombia, 2006)

El plan de manejo del Parque Nacional Natural de Pisba (2006) identificó que las fincas situadas a partir de los 1.800 hasta los 2.300 m.s.n.m., en Socotá, Pisba y Mongua, tienen gran variedad de componentes en sus sistemas de producción, destacándose sus prácticas tradicionales, 
sobre todo en los cultivos de pancoger, gracias a las condiciones de fertilidad de los suelos. Sin embargo, no es extraño que utilicen zonas en el área protegida para el pastoreo de sus animales o para cultivo de papa, arveja o haba.

A pesar de que la ley ampara las áreas de páramo al considerarlas ecosistemas de carácter estratégico, la región del complejo de páramos de Pisba ha sido afectada por la minería. La minería en el páramo es de grava, caliza y predominantemente extracción de carbón, la cual puede ser realizada de muchas formas, pero la más común es la subterránea a pequeña escala. Sin importar el tamaño, la minería demanda grandes cantidades de agua, y además contamina las cuencas hídricas con metales pesados y sustancias químicas. La exploración y explotación de yacimientos de minerales como el carbón, legales e ilegales, ha puesto al páramo en riesgo, pese a las denuncias que se han formulado ante las autoridades respectivas. Así, los conflictos medio ambientales alrededor de la minería en este ecosistema son especialmente problemáticos y apreciables, pues se han otorgado 95 títulos mineros y se calcula la transformación de las coberturas del ecosistema en un 15\%. (Sarmiento, et al., 2017)

\section{Acciones Constitucionales en el Páramo de Pisba}

La justicia procesal y particularmente el acceso a la justicia implica la búsqueda de soluciones por parte de autoridades judiciales y administrativas para la protección de derechos. En el ordenamiento jurídico colombiano, como se mencionó anteriormente, existen acciones para este cometido desde la Jurisdicción de lo Contencioso Administrativo y acciones constitucionales, estas últimas se consagran en la Constitución Política de 1991 en sus artículos 86 y 88, para el primer caso, la acción de tutela con la finalidad de proteger derechos fundamentales y para el segundo, las acciones populares, en búsqueda de protección de derechos colectivos. Estos mecanismos han sido utilizados por parte de los ciudadanos en torno a conflictos ambientales suscitados en el Páramo de Pisba. En este acápite serán objeto de análisis aquellas acciones que por su unidad de materia y relevancia constituyen precedente y fueron resueltas en segunda instancia por el Tribunal Administrativo de Boyacá, asimismo, se estudian las sentencias de la corte constitucional que unifican la jurisprudencia en torno al caso delimitación Páramo de Pisba. Lo anterior, bajo la premisa que el acceso a la justicia "no se limita a la tutela de los derechos ambientales y de la naturaleza, sino que se extiende a la tutela de los derechos de acceso a la información, participación y consulta previa" (Barragán, 2017, p.20). 


\section{Acción de Tutela}

La acción de tutela, instrumento de protección de derechos fundamentales, es el mecanismo más usado por los colombianos desde su creación e inserción en el texto constitucional de 1991, se caracteriza por ser un "procedimiento preferente y sumario...de inmediato cumplimiento... $y$ procederá cuando el afectado no disponga de otro medio de defensa judicial, salvo que aquella se utilice como mecanismo transitorio para evitar un perjuicio irremediable" (Artículo 86, Constitución Política de 1991)

\section{Descripción del pleito}

El proceso de delimitación del Páramo de Pisba liderado por el Ministerio de Ambiente y Desarrollo Sostenible ha suscitado algunas controversias con miembros de la comunidad, así las cosas, un grupo de ciudadanos, activaron el aparato judicial por medio de la acción de tutela solicitando el amparo de sus derechos fundamentales al debido proceso, trabajo y libertad de escoger profesión u oficio; los demandantes laboran en la empresa CI BULK TRADING SUR AMÉRICA LTDA, titular y operadora del contrato de concesión minera para la explotación de carbón en la vereda el mortiño del municipio de Socha, concesión que cuenta con licencia otorgada por Corpoboyacá.

El proceso tuvo trámite en el Juzgado Segundo Administrativo Oral del Circuito Judicial de Duitama (Exp. 2018-00016 02), planteando como problema jurídico "¿Se vulneran derechos fundamentales cuando dentro del trámite de delimitación de páramos se omite garantizar la participación de la comunidad, a través de mecanismos públicos y eficaces?", tutelando además los derechos constitucionales de participación ciudadana y debido proceso de los accionantes y ordenando al Ministerio de Ambiente ajuste y realice convocatoria pública abierta y participativa en la cual sea posible analizar y llegar a acuerdos respecto a la delimitación del páramo y los planes de compensación derivados del proceso.

\section{Argumentación judicial}

El fallo de primera instancia fue apelado por el Ministerio de Ambiente ante el Tribunal Administrativo de Boyacá, quien confirma la sentencia del Juzgado Segundo Administrativo Oral de Duitama. Los principales argumentos de la providencia de segunda instancia son:

- Tomar como precedente las reglas fijadas en la sentencia T-361 de 2017 de la Corte Constitucional, respecto a la protección del derecho de participación ciudadana en los 
Julio - diciembre de 2021

procesos de delimitación de páramos ${ }^{2}$, a partir de la presencia de espacios abiertos, deliberativos y previos al acto administrativo que establezca la delimitación y además el establecimiento de planes para reubicación laboral de las personas que resulten afectadas por la decisión. Aunado a ello, la misma sentencia considera que la participación ciudadana en materia ambiental tiene estatus de ius fundamental.

- La delimitación de los páramos corresponde al Ministerio de Ambiente y Desarrollo Sostenible en obedecimiento a razones de carácter técnico y social, ello en consonancia con el articulado constitucional con enfoque ecológico y que sumado a leyes expedidas por el Congreso de la República como la 1930 de 2018 que busca la gestión integral de los páramos, ha permeado el caso sub examine para llegar a declarar el Páramo de Pisba como Sujeto de Derechos.

- Como consecuencia de la delimitación es fundamental desarrollar procesos participativos con esquemas de gobernanza que permita elaborar planes para la población que resultare afectada bajo la premisa de un enfoque diferencial de derechos.

Del proceso judicial (acción de tutela) mencionado es preciso resaltar que si bien no ha sido la única acción interpuesta, constituye la pionera y determinante para el ejercicio del derecho de participación ciudadana en la delimitación del Páramo de Pisba, es así que subyacen en el conflicto, por un lado, la necesidad de protección del páramo y su consecuente delimitación y por otro, las dificultades de la población de la zona en aspectos laborales - la acción de tutela fue interpuesta por trabajadores de la mina de explotación de carbón mencionada-. Asimismo, como base del conflicto está la participación ciudadana, petición realizada por la ciudadanía ante el desconocimiento por parte de autoridades administrativas, específicamente, el Ministerio de Ambiente, en los procesos de delimitación, haciendo hincapié en la falta de concertación y necesidad de compensación y/o reubicación de los pobladores.

\section{Acciones Populares}

De acuerdo con la Constitución Política de 1991, las acciones populares se encaminan a “... la protección de los derechos e intereses colectivos, relacionados con el patrimonio, el espacio, la seguridad y la salubridad públicos, la moral administrativa, el ambiente, la libre competencia

\footnotetext{
${ }^{2}$ La corte constitucional en sentencia T-361 de 2017 define el procedimiento para la delimitación de los páramos a saber: i) convocatoria amplia, pública y abierta de la comunidad en general para que participe. ii) establecer fase de información para las personas por parte de las autoridades ambientales iii) espacio para consulta e iniciativas, en donde los participantes exponen sus juicios y análisis sobre las alternativas de delimitación iv) concertación entre autoridades y comunidad a partir de un diálogo deliberativo v) proferir acto administrativo de delimitación del páramo por parte de la autoridad ambiental en donde se expongan argumentos de deliberación y razones de apartamiento.
} 
económica y otros de similar naturaleza que se definen en ella." (Artículo 88). Lo que permite recordar que, en el ordenamiento jurídico colombiano, la acción popular es por excelencia el instrumento constitucional que se puede presentar ante el juez de la república para buscar la protección o el cese de la vulneración a aquellos ecosistemas estratégicos, como los páramos, entendiendo su inexorable relación con el derecho colectivo al medio ambiente sano.

\section{Descripción del pleito}

Para el año 2014, la defensoría del pueblo de Boyacá instaura acción popular en contra de Carbones Andinos S.A., Agencia Nacional de Minería, Corporación Autónoma Regional de Boyacá, entre otras entidades, por la aparente violación al derecho colectivo a gozar de un medio ambiente sano y "desarrollo sostenible" (sic) en el municipio de Socha, Boyacá. (Exp. 2014-00223, Tribunal Administrativo de Boyacá)

Lo anterior, con fundamento en la explotación de una mina de carbón subterránea ubicada en la zona del Páramo de Pisba por parte de la empresa Carbones Andinos S.A., que estaba afectando el ecosistema circundante y las algunas fuentes hídricas de vital acceso para los habitantes del municipio de Socha. Lo anterior bajo el contrato de concesión FGD-141.

Se endilga responsabilidad, principalmente, a la empresa por la explotación del yacimiento de carbón, a la Agencia Nacional de Minería por el otorgamiento de título minero en zona de páramo y, a la autoridad ambiental competente, a saber, Corpoboyacá, por el aval de la licencia ambiental sin el debido control y seguimiento. Acciones que, sumadas, han deteriorado el ecosistema y pueden presentar graves amenazas al recurso hídrico.

Al final el Tribunal Administrativo de Boyacá en fallo de primera instancia afirma, entre otras cosas:

- Declaración de responsabilidad por acción parte de la Agencia Nacional de Minería y Corpoboyacá en relación con la vulneración del derecho colectivo al medio ambiente sano y desarrollo sostenible por el otorgamiento del título minero y la licencia ambiental, respectivamente.

- Declara responsable a la empresa Carbones Andinos Ltda., por la vulneración al derecho colectivo al medio ambiente sano al llevar a cabo actividades de explotación minera en zona de páramo. 
- Se ordena el cese de la explotación por parte de la empresa y, así mismo, se ordena llevar a cabo actividades de seguimiento, control y administración de la zona de páramo a entidades como el Ministerio de Ambiente y Desarrollo Sostenible, al municipio de Socha y a Corpoboyacá.

\section{Argumentación judicial}

Los argumentos principales que se pueden resaltar de la mencionada providencia son:

- El área de concesión minera del título FGD-141 se encuentra en zona de páramo, de acuerdo con la delimitación del Atlas de Páramos del Instituto Alexander Von Humboldt del año 2007 y 2013. Por lo anterior, es una zona de alta sensibilidad biológica y ecosistémica. No obstante, la realidad muestra que la transformación del ecosistema producto de las actividades agropecuarias y mineras permite inferir que ya no existen las condiciones del páramo en esta área. Sin embargo, tal condición no es argumento para no ordenar el cese de las actividades mineras entendiendo que la condición actual del ecosistema se debe a la falta de control y vigilancia por parte de las entidades involucradas. En otras palabras, la modificación y alteración del ecosistema se pudo haber prevenido.

- Las actividades de extracción minera han ocasionado impactos negativos en el medio ambiente, como lo son la sedimentación de los suelos y la contaminación a algunos afluentes hídricos de la zona veredal que provee de agua potable al municipio de Socha, vulnerando el derecho colectivo a un medio ambiente sano.

- Con fundamento en el artículo 34 de la ley 685 de 2001 (Código de Minas), artículo 173 de la Ley 1753 de 2015 y la Sentencia C-035 de 2016 de la Corte Constitucional, el Tribunal Administrativo de Boyacá recuerda que si bien Carbones Andinos SA obtuvo el título minero y licencia ambiental con anterioridad al año 2010 (fecha en que la ley 1382 de 2010, prohibía la actividad minera en ecosistemas de páramo; recordando que tal ley fue declarada inexequible con efectos diferidos a dos años) con fundamento en lo explicado por la Corte Constitucional en la sentencia C-035, la escasa protección a los ecosistemas de páramo, sumado a las actividades de extracción que se adelanten en los mismos sin el adecuado seguimiento y control, puede permitir a la autoridad judicial ordenar el cese de las actividades que afectan el ecosistema, lo anterior, debido al "déficit de protección" que puede evidenciarse. 
Con todo lo anterior, se debe agregar un elemento reiterativo en las providencias judiciales de contenido ambiental en los últimos años, a saber, el principio de precaución, pues, según el Tribunal Administrativo de Boyacá, las autoridades ambientales deben orientar sus actuaciones de vigilancia, control y seguimiento teniendo en cuenta que se materialicen daños graves. Las anteriores actuaciones se deberán llevar a cabo, aun sin el conocimiento certero de que la actividad pueda o no ocasionar daños, no obstante, se requiere una carga argumentativa que sustente la decisión.

Vale recordar que la controversia y decisión aquí analizada, fue confirmada en su mayoría por el honorable Consejo de Estado en segunda instancia con fecha de 19 de diciembre de 2018, lo anterior, con algunas modificaciones en la parte resolutiva, en gran medida, atinentes al seguimiento, control y vigilancia por parte de las entidades demandadas y, declarando responsable al Ministerio de Ambiente y Desarrollo Sostenible en gran medida por la ausencia de un proceso participativo que permita celeridad en cuanto a la delimitación del páramo de Pisba.

\section{Sentencias Corte Constitucional}

La delimitación del Páramo de Pisba ha dado lugar a la activación del aparato judicial a partir de acciones constitucionales interpuestas por ciudadanos y por entidades del Estado como la defensoría del pueblo, la conflictividad derivada de estos procesos y la relevancia de los pronunciamientos judiciales en torno a la misma ha conllevado a que sea objeto de estudio en sede de revisión por parte de la Corte Constitucional en las sentencias SU- 399 de 2019 y T- 285 de 2020. La primera de ellas, esto es, la sentencia de unificación, la sala plena de la Corte plantea como problema jurídico a resolver:

“...sí existe carencia actual de objeto por hecho superado y, en caso de que no se esté en presencia de esta figura, entraría a establecer si las entidades accionadas amenazaron los derechos fundamentales al debido proceso, trabajo, libertad de escoger profesión u oficio, participación ambiental y propiedad privada de los accionantes al no socializar ni permitir la participación ambiental bajo los estándares de la sentencia T-361 de 2017, en el trámite de delimitación del Páramo de Pisba". (Sentencia SU- 399 de 2019)

En el análisis del caso la Corte resalta las diferencias entre la acción de tutela y la acción popular, destacando de la última la posibilidad de un debate probatorio y de decisión más amplio que la primera, así para el caso sub examine solicita al Consejo de Estado la sentencia de la sección primera de fecha 19 de diciembre de 2018, en la cual se pronuncia el Tribunal Contencioso 
manifestando que la delimitación del Páramo de Pisba es la única forma para hacer cesar las afectaciones al disfrute de los derechos colectivos a un ambiente sano y la existencia de un equilibrio ecológico, no obstante, para ello, se requiere asegurar la participación ambiental, crear mesas de trabajo, adoptar un plan de manejo de páramo y conformar un comité de vigilancia. Esta decisión es contrastada por la Corte respecto a la petición de amparo incoada por los ciudadanos pidiendo la salvaguarda de sus derechos al trabajo, libertad de profesión u oficio y propiedad privada, bajo la consideración que estos se subsumen en el escenario de la acción popular, en el entendido de la garantía de participación en el trámite de delimitación del Páramo, situación que se presenta como posible hecho vulnerador de sus derechos.

Por su parte, la sala Octava de revisión de la Corte Constitucional en sentencia T-285 de 2020 estudia la acción de tutela bajo el Expediente T-7041100 en el cual se pide el amparo constitucional de los derechos al trabajo, libertad de profesión u oficio y propiedad privada, solicitando la suspensión del trámite de delimitación del Páramo de Pisba hasta tanto no se les permita la participación en el mismo en los términos de la sentencia T-361 de 2017. La Corte en sus consideraciones analiza la carencia de objeto en materia de acción de tutela y reitera jurisprudencia haciendo alusión al pronunciamiento de la sala plena a través de la sentencia SU-399 de 2019, así bajo esas consideraciones resuelve declarar la improcedencia de la acción de tutela por carencia actual de objeto por hecho superado, revocando además la sentencia de tutela en segunda instancia por el Tribunal Administrativo de Boyacá.

Es menester precisar en este punto que, el derecho a la participación ciudadana en asuntos ambientales cada vez ha venido tomando mayor concreción en la jurisprudencia de la Corte Constitucional Colombiana, lo anterior, se denota claramente en la sentencia T-361 de 2017 que establece un procedimiento claro y garantista para que todos los actores que vean interés o afectación a sus derechos en relación con el ecosistema de Páramo de Santurbán (para el caso de la sentencia T-361). Esta sentencia se puede considerar un hito en materia de participación ciudadana en asuntos ambientales, al dar luces respecto al tratamiento que se debe tener en ecosistemas similares en cuanto a dicho asunto.

Vemos así que, para el caso del Páramo de Pisba, tal proceso de participación se adelantó por orden del juez popular en sentencia del 19 de diciembre de $2018^{3}$, sección primera del Consejo de Estado, de acuerdo con los parámetros establecidos por la sentencia T-361 de 2017 y la ley

\footnotetext{
${ }^{3}$ Esta sentencia está contenida en el expediente No. 15001-23-33-000-2014-00223-02
} 
1930 de 2018 (Ley de Páramos), argumento que adoptó la Corte Constitucional en sentencia T285 de 2020 para declarar la improcedencia de la acción de tutela por carencia actual del objeto por hecho superado.

Como se puede evidenciar, las acciones constitucionales que han estado en el centro de la discusión jurídica respecto al Páramo de Pisba, en últimas, lo que han buscado es canalizar el debate hacia un escenario garantista del derecho a la participación ciudadana en asuntos ambientales como eje transversal de la justicia ambiental procedimental, buscando además, proteger los ecosistemas paramunos de aquellas actividades que pueden afectar gravemente sus ciclos biológicos y la relación armónica entre elementos bióticos y abióticos allí inmersos.

\section{Conclusiones}

Si bien no existe consenso sobre el concepto de justicia ambiental, sus aproximaciones se caracterizan por la complejidad de elementos y percepciones que le atañen; así, el análisis histórico indica que es necesario tener en cuenta componentes sociales, políticos, jurídicos, medioambientales, culturales e incluso económicos que conlleven al acceso, participación y garantía de derechos de los ciudadanos y de la naturaleza.

Los elementos de la justicia procesal propuesta por Robert Kuehn en su taxonomía de justicia ambiental, enmarcan el análisis a la hora de entender el estudio de la conflictividad ambiental que puede suscitarse en ecosistemas estratégicos como lo son los ecosistemas de Páramo, particularmente, la participación en la toma de decisiones desde dos ejes, el primero, en materia jurídica, previo a la aprobación de normas que reglamenten y protejan estas situaciones y el acceso y utilización de mecanismos administrativos y jurídicos existentes en pro de la intervención ciudadana, y segundo, desde lo político, a posteriori, esto es, en la fase de implementación de políticas públicas sobre el particular.

La protección normativa frente al acceso a la justicia ambiental ha tenido grandes avances en la última década, así se han aprobado la Declaración de Río, el convenio Aarhus (para el caso europeo) y el Convenio de Escazú ${ }^{4}$, que dentro de sus disposiciones destacan la posibilidad de denunciar ante órganos jurisdiccionales actividades y hechos en contra de la sostenibilidad medioambiental. Así mismo, se resalta que las normas que desarrollan el acceso a la justicia ambiental en la esfera nacional deben ser compatibles con el nivel de protección que la comunidad internacional ha determinado en torno a la protección de los derechos ambientales.

\footnotetext{
${ }^{4}$ A la fecha de este escrito, aún pendiente de ratificación por parte del Estado Colombiano.
} 
La justicia procesal comprende los mecanismos judiciales, administrativos y políticos que permiten a los diferentes actores exigir un mínimo de garantías o protección a los ecosistemas; en el caso bajo estudio, se evidenció que los mecanismos de protección constitucionales establecidos por el ordenamiento jurídico colombiano han sido efectivamente garantizados y resueltos por parte de las autoridades judiciales en relación con la protección y conservación del ecosistema de Páramo de Pisba.

La conflictividad en los ecosistemas estratégicos en Colombia ha venido en constante incremento en los últimos años; la necesidad de protección de los páramos ha hecho visible las falencias que existen respecto de las medidas que las autoridades ambientales han tomado y, sin duda, han puesto sobre la mesa el debate entre la protección ambiental y la búsqueda del crecimiento económico de algunos particulares por encima de los derechos colectivos y la riqueza natural.

El Páramo de Pisba, por su ubicación y características, representa el acceso a ciertos servicios ecosistémicos esenciales para las poblaciones aledañas, como lo son el agua potable y el alimento, por lo que, las acciones judiciales que se han tomado en la búsqueda de su protección, no solamente materializan un acceso a la justicia ambiental en un sentido procesal, sino que permiten poner en acción el aparato jurídico administrativo del Estado en aras de visibilizar las afectaciones graves que pueden darse a estos ecosistemas, ejemplo de ello, es la interposición de acciones de tutela y populares como mecanismos constitucionales que garantizan el acceso a una justicia ambiental, las cuales han permitido que los jueces tomen parte activa en la instrucción de órdenes encaminadas no solamente a una protección superficial de los ecosistemas, sino incluso lleguen a replantear la relación instrumental tradicional del hombre con la naturaleza.

Lo anterior, sin duda ha consolidado el rol activo del juez en aras de la construcción de un derecho ambiental centrado en las comunidades y la naturaleza, buscando preservar y proteger el capital natural por su valor en sí mismo y, por el bienestar de las futuras generaciones.

\section{Referencias}

Barragán, D. (2017) Derechos de acceso en asuntos ambientales en el Ecuador: Hacia el desarrollo de una actividad minera respetuosa del entorno y las comunidades. Serie Medio Ambiente y Desarrollo, $N^{\circ} 165$. Comisión Económica para América Latina y el Caribe https://repositorio.cepal.org/bitstream/handle/11362/41985/1/S1700598 es.pdf 
Julio - diciembre de 2021

Bellmont, Y.S., (2012) El concepto de justicia Ambiental: Reflexiones en torno a la Jurisprudencia constitucional colombiana del siglo XXI. Tesis de Maestría - Universidad Nacional de Colombia. http://www.bdigital.unal.edu.co/8706/1/905060.2012.pdf

Comisión Económica para América Latina y el Caribe (CEPAL), (2018). Acuerdo Regional sobre el Acceso a la Información, la Participación Pública y el Acceso a la Justicia en Asuntos Ambientales en América Latina y el Caribe. Publicación de las Naciones Unidas. Recuperado de: https://repositorio.cepal.org/bitstream/handle/11362/43595/1/S1800429 es.pdf

Congreso de la República de Colombia (27 Julio de 2018). Ley No. 1930 del 27 Julio de 2018, "por medio de la cual se dictan disposiciones para la gestión integral de los páramos en Colombia" recuperado de: http://es.presidencia.gov.co/normativa/normativa/LEY\%201930\%20DEL\%2027\%20DE \%20JULIO\%20DE\%202018.pdf

Convenio de Aarhus (25 de junio de 1998). Convenio sobre el acceso a la información, la participación del público en la toma de decisiones y el acceso a la justicia en materia de medio ambiente Aarhus, Dinamarca. https://www.oas.org/es/sla/ddi/docs/acceso informacion desarrollos convenio aahr us.pdf

Corte Constitucional (2018, 15 de noviembre) Sentencia SU-123. Sala Plena (Alberto Rojas Ríos. Rodrigo Uprimny Yepes. M.P.)

Corte Constitucional (2019, 29 de Agosto) Sentencia SU-399. Sala Plena (José Fernando reyes Cuartas. M.P.)

Corte Constitucional (2020, 3 de Agosto) Sentencia T-285. Sala Octava de Revisión (José Fernando reyes Cuartas. M.P.)

Defensoría del Pueblo, Defensoría Delegada para los Derechos Colectivos y del Ambiente, (2014). Informe Defensorial: La problemática de minería en el municipio de Tasco, Boyacá.

EPA (2013). Environmental Justice-Related Terms As Defined Across the PSC Agencies 
Julio - diciembre de 2021

Gosine, A., \& Teelucksingh, C. (2008). Environmental justice and racism in Canada: An introduction. In CANADIAN GEOGRAPHER-GEOGRAPHE CANADIEN. 55(4), pp. 529-530). http://basesbiblioteca.uexternado.edu.co:2048/login?url=http://search.ebscohost.com

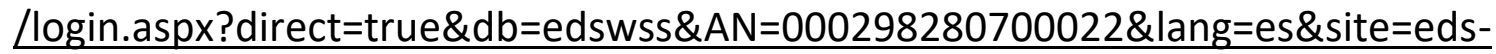
$\underline{\text { live\&scope }=\text { site }}$

Greenpeace Colombia, (2013). Páramos en peligro. El caso de la minería de carbón en Pisba. http://greenpeace.co/pdf/paramos/Informe\%20P\%C3\%A1ramos\%20en\%20peligro.pdf

Guzmán Jiménez, L. (12 de noviembre de 2018). Medio ambiente y acceso a la justicia: ¿son los tribunales ambientales una solución para abordar los conflictos ambientales en Colombia?. https://medioambiente.uexternado.edu.co/medio-ambiente-y-acceso-a-lajusticia-son-los-tribunales-ambientales-una-solucion-para-abordar-los-conflictosambientales-en-colombia/

Hernández Sampieri, R., Fernández Collado, C. \& Baptista Lucio, M. (2010). Metodología de la investigación. (5.a ed.). Editorial: McGRAW-HILL / Interamericana Editores.

Hervé Espejo, D. (2010). Noción y Elementos de la Justicia Ambiental: Directrices para su aplicación en la Planificación Territorial y en la Evaluación Ambiental Estratégica. Revista de derecho (Valdivia), 23(1), pp. 9-36. https://dx.doi.org/10.4067/S0718$\underline{09502010000100001}$

Hervé Espejo, D., \& Rebolledo, S. (2013). La Justicia Ambiental en el Ordenamiento Jurídico Ambiental Chileno. Astrolabio, En: https://revistas.unc.edu.ar/index.php/astrolabio/article/view/5599

Ibarra Barreras, M.F. \& Moreno Vásquez, J.L. (2017) La justiciar Ambiental en el Río Sonora. RevIIES Revista de Ciencias Sociales y Humanas, 10(10), pp. 135-155. https://www.redalyc.org/jatsRepo/5535/553559586012/movil/index.html

Kuehn, R. (2000). A taxonomy of environmental justice. Environmental Law Reporter, 30, 10681.

Meneses Moreno L., Velasco Cáceres L., Velasco Cordero P., \& Rivera H. (2006). Plan de manejo del parque nacional natural Pisba 2005-2009, Parques Nacionales de Colombia. https://www.parquesnacionales.gov.co/portal/wpcontent/uploads/2013/12/pnnPISBA.pdf 
Julio - diciembre de 2021

Mesa Cuadros, G. (2015) Conflictividad y desplazamiento Ambiental: Elementos jurídicopoliticos de Justicia Ambiental y reparación a sociedades tradicionales. Revista catalana de Dret Ambiental VII $\quad$ pp.1-50 https://www.raco.cat/index.php/rcda/article/view/307066/397045

Mesa Cuadros, G. (2018). Una idea de justicia ambiental: elementos de conceptualización y fundamentación. Editorial Universidad Nacional de Colombia. https://elibro.net/es/lc/bibliojdc/titulos/129953

Naciones Unidas sobre medio ambiente y desarrollo (14 de junio de 1992) Declaración de Río sobre el medio ambiente $y$ desarrollo. https://www.un.org/spanish/esa/sustdev/agenda21/riodeclaration.htm

Ramírez Guevara, S. J., Galindo Mendoza, M. G., \& Contreras Servín, C. (2015). Justicia ambiental: Entre la utopía y la realidad social. Culturales, 3(1), pp. 225-250. http://www.scielo.org.mx/scielo.php?script=sci arttext\&pid=S1870$11912015000100008 \& \operatorname{lng}=e s \& t \operatorname{lng}=e s$.

Ruhl, S., \& Ostar, J. (2016). ENVIRONMENTAL JUSTICE. GPSolo, 33(3), pp. 42-47. http://www.jstor.org/stable/44736908

Russ, A., \& Krasny, M. E. (Eds.). (2017). Urban Environmental Education Review. Cornell University Press. http://www.jstor.org/stable/10.7591/j.ctt1qv5qhq

Sarmiento Pinzón C., Cortés-Duque J., \& Suárez Mejía, A. (2013). Aportes a la conservación estratégica de los páramos de Colombia: actualización de la cartografía de los complejos de páramo a escala 1:100.000. Instituto de Investigación de Recursos Biológicos Alexander Von Humboldt http://repository.humboldt.org.co/handle/20.500.11761/31406

Sarmiento. C, Osejo. A, Ungar. P \& Zapata. J (2017) Páramos habitados: desafíos para la gobernanza ambiental de la alta montaña en Colombia. Biodiversidad Practica 2 (1) pp. 122-145. http://revistas.humboldt.org.co/index.php/BEP/article/view/480/469

Tribunal Administrativo de Boyacá (2019, 02 de octubre) Sentencia decide recurso de apelación acción de tutela Expediente_2018-00016 02 (Clara Elisa Cifuentes Ortíz, M.P.)

Tribunal Administrativo de Boyacá (2017, 21 de marzo) Sentencia primera instancia acción popular Expediente 2014-00223 (Fabio Iván Fanador García, M.P.) 